\title{
NON-PSYCHOLOGICAL DEEP STRUCTURES?
}

David S. Rood

University of Colorado

\begin{abstract}
There is a certain amount of awkward incompatibility between the linguist's use of underlying syntactic structures and his assertions that such structures have psychological validity, particularly in the light of some recent psychological research. Nevertheless, the 1inguist's use of deep structures can be Justified if we will re-state our goals and claim to describe langie rather than competence.
\end{abstract}


The distinction between underlying surface structures in both syntax and phonology is very useful in the discussion and description of languages. One clear demonstration of this assertion is simply the large number of instances in which a linguist discussing a problem makes use of the distinction.

At the same time, there exists an immense amount of debate and/or embarrassment about just what the 'underlying' structures are. I should like to speculate about some of the reasons behind this paradoxical phenomenon, and offer a potentially salutary suggestion about the statement of goals in linguistics.

The concept of syntactic deep structures is inextricably intertwined with the distinction between competence and performance. This distinction has been part of transformational generative dogma at least since Chomsky's Aspects (Chomsky 1965: 3-4 and refs. there to earlier discussion). Initially, it was a defense against the structuralist position that linguists should analyze all and only the utterances produced by native speakers, ignoring introspective comments by those speakers (Chomsky 1965:193-194 = Chapter 1, fn. 1). In his attempt to set up a formal model of a grammar of a language, Chomsky proposed that this be a model of what a speaker knows, perhaps unconsciously, about his language. Consequently, performance 'errors' were climinated from the data used for analysis, and introspection and the discussion of mental activity were allowed into linguistic analyses. In short, speakers were again (i.e., as before Bloomfield) 
allowed to have brains and linguists were admonished to acknowledge and make use of those brains. A continuing reflection of this position appears in statements such as this in Fodor, Fodor and Garrett (1975:523): "structural descriptions are intended to be psychologically real."

The word 'model' for Chomsky never referred to scale models or working replicas of a speaker's brain, although it was often understood that way. Instead, Chomsky obviously intended 'model' to mean a device ('a little black box') which, given the same input as a speaker was given, would produce the same output (Chomsky 1965: 8-9). The inner workings of the brain and the black box were never expected to be the same, although many researchers either hoped or expected that they would turn out that way ( $\mathrm{Cf}$. Chapter 5 in Fodor, Bever and Garrett 1974).

Perhaps because of Chomsky's disclaimers about any isormorphism of brain processes and transformational rules, many linguists have fortunately devoted their efforts to working out complex structures purporting to account for the relatedness of certain groups of sentences, without much concern about the psychological reality of their hypotheses. Although the data admissible to such analyses are invariably in the form of grammatical versus ungrammatical sentences ("in my dialect"), the analysis is always assumed to be one of speaker competence. In effect, then, the linguist is purporting to tell the speaker what the latter knows about his language but cannot express. Because the goal of Iingristic description is said to be a description of competence, every 
liriguistic analysis using transformational devices must at least pay lip service to psychological reality.

There is, however, a growing body of data which suggest that speaker competence as originally defined is not what elegant gramars describe. The now-famous Maori example from Hale (1971), the Kekchi experiences of Lyle Campbell (1974), and the numerous unpublished frustrations of teachers of elementary linguistics courses and of second languages suggest that true speaker competence is not in the form of simple but highly abstract lexical entries and complex rules at all, but rather in the form of relatively arbitrary lists plus a few simple combinatory rules. Similar data are supplied by the observations of Householder (1971:21 and $290 \mathrm{ff}$ ) with respect to "centos" or prememorized phrases ready to be 'plugged in' at appropriate points in a poem or conversation. It would begin to seem then, that our elegant and hard-wrought grammars are not grammars of competence at all. What are they then? And perhaps as importantly, should they be abandoned as unrealistic, futile exercises?

The answer to the second question must be emphatically negative: rules applying to abstract underlying structures have a linguistic descriptive and explanatory power unequaled by any other kind of grammar (cf. Paninin!), even if, as now seems likely, they turn out not to have any generalized psychological validity. Linguists should continue to describe languages, and probably not worry about whether they are modeling speakers or not. This is not to say that questions such as those of language acquisition, complex sentence processing, perception strategies, and memory are not important; they are extremely important to anyone who 


\section{$-9-$}

\section{?}

has to deal with language as mani festod in pecile, irom psychoaralysts to second lanmage teachers and spech therapists. But perhaps linguists should stop claiming to describe competence and odmit to being more concerned about the properties of languages than of speakers.

To a great extent, statements of scientilic goals are necessarily personal: we would like linguistic theory to deal wi th those aspects of language in which we are interested. ${ }^{1}$ If language processing excites our curiosity, we want to formulate a theory of language which conforms to our best understanding of the mechanisms of the processing. But there are other fascinating aspects of language.?

As Saussure pointed out many ysars ago, there is a very importent sense in which no language can be complete in any one speaker. Fvery language is the property of a whole community of speakers, no two of whom possess exactly the same parts of it.

I should like to suggest that good linguistic descriptions should

IOne of the most blatant recent examples of corfusioi of personal interests with the gonls of the ield is tieb (1976). He proposes that, trans formational-penerative prammar, if pursued, will prevent linguistics from attaining j.ts primary goal, which he defines quite aifferentily from what I consiar ing goals as a linguist to he.

The problem of overt statements about goal formulation seems to plague linsujstics periodjcally. Such self-conscious attempts to say what they were doing were at, the heart, of some of the troubles of neoBloomfiolian structuralists in the $1960^{\prime}$ s ton: they were accused of being mrealistic, and their own statements about, what, they were doing were cited in support of such criticism. Nowadays it is generally recomized that the structuralists never really did what they said they wore doins, so the criticisns were in fact invalid. The prosent-iny di 1 emm is similar: the goals of linglistics are stated in psycholoeical terms (deseribe competence, e.p.), yet psychologists have trouble validating the results (e.s., Fodor, Fodor and Garrott 1975:516, "That is recolled in remberirg a senteres corresponts to none of its linoustionlly notivated remesontations"). Conoquently, lineuists aro acoused of falline their statal pouls. 
$-\mathrm{R} 6-$

be considered grammars of languages, not of speakers, and that the goal of Iinguistics should be the formulation of such grammars. In this suggestion, I am using language in the sense of Saussure's langue, a sociological entity rather than a psychological one, and a system which is the property of a community, probably incomplete in any one individual member of the community. If we purport to be describing such an entity, then the internal properties of the grammars themselves become important, but the way speakers react to these properties, whether unconsciously or consciously, becomes irrelevant. Linguistics and the psychology of language again become separate goals, and neither need be terribly worried that the results of the other will invalidate its own. Language can be described apart from idiolects, as a complex but rigidly rule-governed structure which changes in time in regular and partially predictable ways as it responds to various kinds of pressures from within and without. Speaker competence can still be ascertained, of course, but it will not be that which the grammar of a language describes, since the latter is complete only in a much larger organism. ${ }^{3}$

${ }^{3}$ Steinberg (1975) has traced with great care the development of a psychological attitude toward linguistic structures in Chomsky's own writings. He concludes that Chomsky's formalisms are inherently incompatible with his psychological assertions, and that Chomsky's own theoretical position thus contains internal contradictions. To resolve the contradictions, Steinberg asserts, Chomsky must renounce either the clains to psychological validity or the formalisms of his linguistic theory. By arguing above that the object of a transformational grammar be considered langue rather than competence, I suspect I am arguing for retaining the formalisms and rejecting the psychology. 


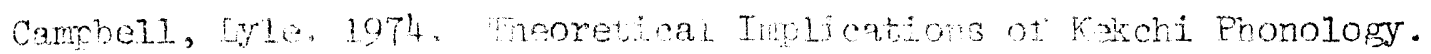
IJAL, $40: 200-28$. MIT.

Thoistr, Noan. 1965. Apects of tho moom of syntax. Cambridge:

Fodor, J.A., T.G. Pever and M.E. Carrott. 197t. The Fsychology of Language. Ner lork: Murew Hitle

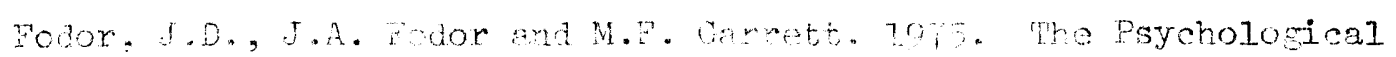

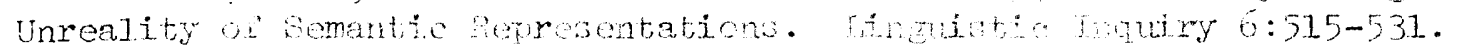

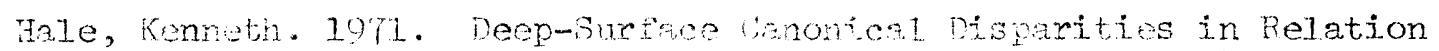
to Andlysis and Change: An Australinn Exame. 1973. Pp. $401-458$. T. Sobok, ed. Current prends in Lingustics, vol. 11. Reported in $P$. Kiparsky, distorial ingustics, in H.o. Dingrali, ed., A Survey of tinguistic Goience. Wingustios Program, University of Maryland, 1971, Pp. $390-59+$

Touscholder, Frod W. L971. Tingustis Soevulations. Camomidge: Cambridge University Press.

Liob, Hans-Heinrioh. 1976. Reasons for Abanconing Generative Grammar. Los. Sciences 39:2L-2e.

Steinoexs, Danny D. 1975. Monsiry: From Furmalism to Mentalism and Invalidity. Working Papers in Linglistics: Dept. of Linguistics, University of Hawai, $7(3): 89-126$. 